\title{
Brucella Non-Neutrocytic Bacterascites in a Patient with Chronic Liver Disease
}

\author{
Bruno Marmelo ${ }^{1,2}$, Telma Pereiro ${ }^{1}$, Paula Sousa ${ }^{1,3}$, Joana Capelo ${ }^{1}$, Adelino Carragoso \\ ${ }^{1}$ Internal Medicine Service, Centro Hospitalar Tondela-Viseu, E.P.E., Portugal \\ ${ }^{2}$ Cardiology Service, Centro Hospitalar Tondela-Viseu, E.P.E., Portugal \\ ${ }^{3}$ Gastroenterology Service, Centro Hospitalar Tondela-Viseu, E.P.E., Portugal
}

Received: 17/07/2015

Accepted: 21/07/2015

Published: $24 / 07 / 2015$

How to cite this article: Marmelo B, Pereiro T, Sousa P, Capelo J, Carragoso A. Brucella non-neutrocytic bacterascites in a patient with chronic liver disease. EJCRIM 2015;2:doi: 10.12890/2015_000252

Conflicts of Interests: The authors declare that they have no competing interests.

Acknowledgements: The authors declare they have patient's permission.

This article is licensed under a Commons Attribution Non-Commercial 4.0 License

\section{ABSTRACT}

Objectives: To report a case of Brucella peritonitis.

Patient and Methods: We describe the case of a patient and present a brief review of the few published reports.

Results: The patient had alcoholic cirrhosis of the liver and was diagnosed with Brucella non-neutrocytic bacterascites.

Conclusion: Brucellosis is a common zoonosis with worldwide distribution. It is a systemic disease with the potential to predominantly affect one organ or a specific system (focal brucellosis). However, peritoneal focalization of this disease is a very rare presentation.

\section{LEARNING POINTS}

- Infection of peritoneal fluid can occur in spite of a low ascitic leucocyte count.

- Although rarely, Brucella spp. can be the causative agent of peritoneal fluid infection, especially in endemic areas.

- Brucella species should be considered potential causative agents of peritoneal fluid infection in patients with risk factors such as chronic liver disease, ventriculoperitoneal shunts and continuous peritoneal dialysis.

\section{KEYWORDS}

Brucellosis, Brucella, Brucella mellitensis, peritonitis, spontaneous bacterial peritonitis, monomicrobial nonneutrocytic bacterascites

\section{INTRODUCTION}

Brucellosis is a global zoonosis with a high prevalence in certain areas such as the Mediterranean basin, the Middle East, North Africa, India and Central Asia, Mexico and South America, in accordance with reservoir distribution ${ }^{[1,2]}$. Brucellosis is endemic in Portugal although its incidence has been decreasing in recent years ${ }^{[1,3]}$.

Brucellosis in humans is caused by one of four species: Brucella abortus, B. mellitensis, B. suis and B. canis. Animal reservoirs include sheep (B. mellitensis), cattle and bison (B. abortus), pigs, deer and elk (B. suis), and dogs, foxes and coyotes (B. canis) ${ }^{[1,2,3]}$. Brucellosis is transmitted to humans by direct contact with contaminated animals, ingestion of infected dairy products or inhalation of infectious aerosols ${ }^{[1,2]}$.

Although brucellosis can affect any organ or tissue, it usually presents with non-specific symptoms such as malaise, undulating fever, chills, night sweats, weight loss, myalgia and arthralgia ${ }^{[2,3]}$. The infection may present with or be complicated by specific organ involvement (focal brucellosis) ${ }^{[1,2]}$. Spontaneous bacterial peritonitis due to Brucella spp. is very rare, even in endemic areas with a high prevalence of brucellosis ${ }^{[4]}$. Most patients have common risk factors, such as chronic liver disease, ventriculoperitoneal shunts and continuous peritoneal dialysis ${ }^{[4]}$.

We present a case of peritoneal brucellosis and we briefly review the few published reports.

\section{CASE REPORT}

A recently abstemious 62-year-old male with alcohol-related Child-Pugh class C cirrhosis of the liver presented to the emergency department complaining of fatigue, anorexia, lumbar and abdominal pain and urinary incontinence over the previous month. He denied fever, gastrointestinal changes or any other complaints. The patient had had malaria in his 20 's. He did not take any medications.

On admission he was conscious, apyretic, normotensive, icteric and malnourished. At abdominal examination, an uncomplicated umbilical hernia was observed. The patient had abdominal pain, mostly in the left flank, without peritoneal signs, a non-tense ascites was present; 
and the spleen was palpable. The neurological examination was normal. Other physical signs were unremarkable.

The relevant laboratory data are presented in Table 1. Abdominal ultrasonography identified moderate to abundant ascites and heterogeneous liver and spleen.

\begin{tabular}{|c|c|c|}
\hline Variable & Patient & Reference Range \\
\hline Haemoglobin (g/dl) & 10.2 & $14-18$ \\
\hline Median corpuscular volume (fl) & 108 & $80-95$ \\
\hline $\mathrm{WBC}\left(/ \mathrm{mm}^{3}\right)$ & 4,200 & $4,500-11,500$ \\
\hline Platelet count $\left(/ \mathrm{mm}^{3}\right)$ & 132,000 & $150,000-450,000$ \\
\hline Prothrombin time (sec) & 17.1 & $9.9-12.8$ \\
\hline Urea (mg/dl) & 22 & $16-42$ \\
\hline Creatinine (mg/dl) & 0.7 & $0.6-1.3$ \\
\hline Sodium (mEq/l) & 132 & $136-145$ \\
\hline Potassium (mEq/l) & 3.3 & $3.5-4.5$ \\
\hline Aspartate aminotransferase (IU/I) & 78 & $4-43$ \\
\hline Alanine aminotransferase (IU/I) & 30 & $4-43$ \\
\hline Alkaline phosphatase (IU/I) & 239 & $25-100$ \\
\hline Lactate dehydrogenase (IU/I) & 552 & $200-480$ \\
\hline$\gamma$-Glutamyl transpeptidase (IU/I) & 34.8 & $7-49$ \\
\hline Total bilirubin (mg/dl) & 5.2 & $0.3-1.2$ \\
\hline Direct bilirubin (mg/dl) & 3.43 & $0.1-0.5$ \\
\hline Amylase (IU/I) & 37 & $8-53$ \\
\hline Lipase (IU/I) & 44 & $6-51$ \\
\hline Total proteins (g/dl) & 7.4 & $6.6-8.7$ \\
\hline Albumin (g/dl) & 2.2 & $3.5-5.0$ \\
\hline C-reactive protein $(\mathrm{mg} / \mathrm{dl})$ & 6.19 & $<0.5$ \\
\hline
\end{tabular}

Table 1: Laboratory data

A diagnostic paracentesis was done and a yellow fluid was obtained. The biochemical examination of the fluid was consistent with transudate (protein $1.3 \mathrm{mg} / \mathrm{dl}$, LDH $148 \mathrm{IU} / \mathrm{I}$ ) secondary to portal hypertension (serum-to-ascites albumin gradient $1.7 \mathrm{mg} / \mathrm{dl}$ ), and a glucose level of $134 \mathrm{mg} / \mathrm{dl}$; the cytological examination revealed a leucocyte count of $10 \mathrm{cells} / \mathrm{mm} 3$ with mononuclear cell predominance and 50 erythrocytes/mm3; the gram stain was negative. In light of these results, the patient was discharged with symptomatic treatment. Two weeks later the ascitic fluid grew Brucella mellitensis, so the patient was admitted to the hospital.

The patient denied consuming unpasteurized milk products. However, his neighbour had goats which were regularly in the vicinity of his house. The Rose Bengal test was positive as well Wright's reaction with a titre $>1 / 1,280$.

Treatment with oral doxycycline $100 \mathrm{mg}$ twice daily and intravenous gentamicin $5 \mathrm{mg} / \mathrm{kg}$ daily was started.

Persistent complaints of lumbar pain associated with urinary incontinence led to the ordering of a magnetic resonance imaging scan of the spine. This investigation excluded inflammatory lesions.

The patient evolved favourably, with clinical improvement. He was discharged after 7 days of doxycycline and gentamicin, continuing treatment with doxycycline for another 5 weeks.

Despite the benign course of the infection under treatment, the patient returned to the hospital 29 days after discharge with an incarcerated umbilical hernia but refused urgent surgery. He died 11 days later of septic shock and hepatic encephalopathy, complications of his previous condition.

\section{DISCUSSION}

Infection of peritoneal fluid in liver cirrhosis results from prolonged bacteraemia secondary to compromised host defences associated with intra-hepatic shunting of colonized blood and defective bactericidal activity of the ascitic fluid ${ }^{[5]}$. The spectrum of ascitic fluid infections includes spontaneous bacterial peritonitis, culture-negative neutrocytic ascites and monomicrobial non-neutrocytic bacterascites.

The low leucocyte count and the positive culture classify this case as monomicrobial non-neutrocytic bacterascites. This is a common variant of ascitic fluid infection that may resolve without treatment or may progress to spontaneous bacterial peritonitis ${ }^{[5,7]}$. In this case, the low leucocyte count in the ascitic fluid raised a doubt about fluid contamination; however, blood serology tests confirmed the infection. The most probable portal of entry in this case is via inhalation, as the patient denied direct contact with possible infectious animals or 


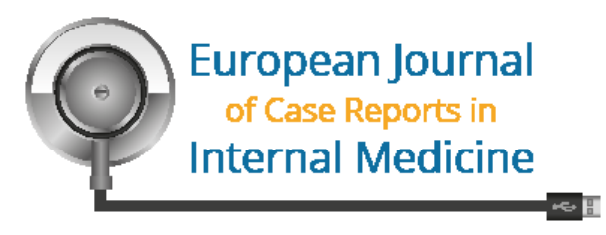

ingestion of non-pasteurized dairy products.

Brucella spp. is a very rare causative agent of peritonitis. On 17 July 2015, we searched PubMed using the terms 'peritonitis AND brucella', 'peritoneal AND brucella' and 'ascites AND brucella'. We only found 35 cases of peritonitis caused by Brucella spp. Just one of them had been diagnosed in Portugal ${ }^{[8]}$.

Uncomplicated brucellosis in (non-pregnant) adults and children over 8 years of age is usually treated with a combination of doxycycline and an aminoglycoside, typically streptomycin ${ }^{[1,2,3]}$. However, despite incomplete clinical evidence, fewer adverse effects are seen with the combination of doxycycline and gentamicin ${ }^{[9]}$.

As no specific treatment has been described for ascitic fluid infection due to Brucella, we decided in favour of a regimen with gentamicin for 7 days and doxycycline for at least 6 weeks ${ }^{[2,9]}$, because of its fewer adverse effects compared to streptomycin, and the need for shorter intravenous treatment with a consequently shorter hospital stay ${ }^{[9]}$.

Patients with cirrhosis can have multiple causes of death and spontaneous bacterial peritonitis is responsible for increased mortality. In this case, the death was not directly caused by the infection, but indirectly resulted from complications of the patient's chronic advanced liver disease (Child-Pugh class C).

\section{CONCLUSIONS}

Based on bacterial growth in the fluid and confirmatory blood serology, our patient was diagnosed with peritoneal fluid infection due to Brucella mellitensis in spite of a low ascitic cell count. The patient had a risk factor (chronic liver disease) and lived in an endemic area of brucellosis.

Brucella species should be considered potential causative agents of peritoneal fluid infection in patients with particular clinical features living in endemic areas.

\section{REFERENCES}

Pappas G, Akritidis N, Bosilkovsky M, Tsianos E. Brucellosis. N Engl J Med 2005;352:2325-2336.

Corbell MJ. Brucellosis in humans and animals. Geneva: WHO, FAO, OIE;2006.

Pessegueiro P, Barata C, Correia J. Brucelose - uma revisão sistematizada. Medicina Interna 2003;10:91-100.

Hatipoglu CA, Yetkin A, Ertem GT, Tulek N. Unusual clinical presentations of brucellosis. Scand J Infect Dis 2004:36:694-697.

Alaniz C, Regal RE. Spontaneous bacterial peritonitis: a review of treatment options. P\&T 2009;34:204-210.

Runyon BA. Monomicrobial nonneutrocytic bacterascites: a variant of spontaneous bacterial peritonitis. Hepatology 1990:12.710-715.

Caruntu FA, Benea L. Spontaneous bacterial peritonitis: pathogenesis, diagnosis, treatment. J Gastrointest Liver Dis 2006;15:51-56.

Caruntu FA, Benea L. Spontaneous bacterial peritonitis: pathogenesis, diagnosis, treatment. J Gastrointest Liver Dis 2006;15:51-56.

8. Ferreira AO, Martins LN, Marinho RT, Velosa J. Spontaneous bacterial peritonitis by Brucella in a cirrhotic patient. BMJ Case Rep 2013; pii: bcr2013008629. doi: 10.1136/bcr-2013-008629.
9. Roushan MRH, Mohraz M, Hajiahmadi M, Ramzani A, Valayati AA. Efficacy of gentamicin plus doxycycline versus streptomycin plus doxycycline in the treatment of brucellosis in humans. Clin Infect Dis Roushan MRH, Mohraz 